\title{
Characterization of the phenolic and antioxidant profiles of selected culinary herbs and spices: caraway, turmeric, dill, marjoram and nutmeg
}

\author{
Anna VALLVERDÚ-QUERALT ${ }^{1,2}$, Jorge REGUEIRO ${ }^{3}$, José Fernando Rinaldi ALVARENGA4, \\ Miriam MARTINEZ-HUELAMO ${ }^{1,2}$, Leonel Neto LEAL ${ }^{5}$, Rosa Maria LAMUELA-RAVENTOS ${ }^{1,2 *}$
}

\begin{abstract}
Culinary herbs and spices have long been considered essentially as flavor enhancers or preservatives, with little attention given to their potential health-promoting properties. Nevertheless, recent research has shown them to be significant dietary sources of bioactive phenolic compounds. Despite noteworthy efforts performed in recent years to improve our knowledge of their chemical composition, a detailed phenolic profile of these plant-based products is still lacking. In the present work, antioxidant activities and phenolic composition of five herbs and spices, namely caraway, turmeric, dill, marjoram and nutmeg, have been studied. The use of liquid chromatography coupled to LTQ-Orbitrap mass spectrometry enabled the identification of up to 42 phenolic compounds. To the best of our knowledge, two of them, apigenin- $C$-hexoside- $C$-pentoside and apigenin- $C$-hexoside- $C$-hexoside have not been previously reported in turmeric. Qualitative and quantitative differences were observed in polyphenol profiles, with the highest phenolic content found in caraway. Multivariate statistical treatment of the results allowed the detection of distinctive features among the studied herbs and spices.
\end{abstract}

Keywords: antioxidant capacity; culinary herbs; HPLC-ESI-LTQ-Orbitrap; polyphenols; spices.

Pratical Application: Culinary herbs and spices have been used as preservative agents to extend the shelf-life of food and also to enhance the flavor and organoleptic properties of different types of food. Interest in the bioactive phenolic compounds of these plant-based products is currently growing due to their health benefits. The aim of the current study was to extensively analyse the phenolic profile of dill, nutmeg, marjoram, turmeric and caraway to help industries to produce spices with higher content of polyphenols.

\section{Introduction}

Culinary herbs and spices have been long used as preservative agents to extend the shelf-life of food and also to enhance or improve the flavor and organoleptic properties of different types of food due to their sensory properties (Park, 2011; Kivilompolo et al., 2007). Interest in the bioactive phenolic compounds of these plant-based products is currently growing. Recent research has shown culinary herbs as a dietary source of antioxidant polyphenols (Hinneburg et al., 2006; Wojdyło et al., 2007), which has increased the interest in the study of their phenolic composition and antioxidant properties.

In the search for phytochemicals that are beneficial for human health, polyphenols are an attractive target, due to their antimicrobial, digestive stimulant, anti-inflammatory, antioxidant and anticarcinogenic activities (Shobana \& Naidu, 2000). Flavonoids and hydroxycinnamic acids provide free-radical scavenging, modulation of enzymatic activity, metal chelation and inhibition of cellular proliferation. Additionally, polyphenols can extend the shelf-life of lipid-rich foods (Kivilompolo et al., 2007).
Some authors have previously studied the contribution of several widely culinary herbs and spices to the total intake of dietary antioxidants (Halvorsen et al., 2002; Hinneburg et al., 2006; Wojdyło et al., 2007). For instance, rosmarinic acid, along with other compounds present in rosemary (e.g. carnosol, rosmanol, and epi-rosmanol), has shown potent antioxidant activities (Herrero et al., 2010), as possess thyme, oregano and marjoram (Hinneburg, et al., 2006; Amarowicz et al., 2009). However, a comprehensive identification of the phenolic profile of caraway, turmeric, dill, marjoram and nutmeg is still lacking.

For this purpose, high-resolution/accurate-mass measurement (HRAM) mass spectrometry techniques can provide abundant information for the structural elucidation of a wide range of polyphenol compounds. The combination of Orbitrap technology with a linear ion trap (LTQ) has been shown to enable fast, sensitive and reliable detection and identification of small molecules in plant-based extracts (Vallverdú-Queralt et al., 2014; Regueiro et al., 2014).

${ }^{1}$ Nutrition and Food Science Department, Reference Network Food Technology - XaRTA, Research Institute of Nutrition and Food Safety - INSA, Pharmacy School, University of Barcelona, Spain

${ }^{2}$ Centro de Investigación Biomédica en Red de la Fisiopatología de la Obesidad y Nutrición - CIBEROBN, Instituto de Salud Carlos III, Spain

${ }^{3}$ Nutrition and Bromatology Group, Department of Analytical and Food Chemistry, Faculty of Food Science and Technology, University of Vigo, Spain

${ }^{4}$ Department of Food and Nutrition, School of Pharmaceutical Science, São Paulo State University, São Paulo, SP, Brazil

${ }^{5}$ Nutreco Research and Development, Boxmeer, The Netherlands

*Corresponding author: lamuela@ub.edu 
The aim of the current work was to extensively study the phenolic profile of several herbs (caraway, turmeric, dill, marjoram and nutmeg) using an approach based on HPLC coupled to ESI-LTQ-Orbitrap mass spectrometry. In total, 42 phenolic compounds could be identified through HRAM mass spectrometry, two of them, apigenin- $C$-hexoside- $C$-hexoside and apigenin- $C$-hexoside- $C$-pentoside, hitherto unreported in turmeric. Phenolic compounds and hydrophilic antioxidant capacity were shown to be responsible for the differences among these herbs and spices.

\section{Materials and methods}

\subsection{Standards and reagents}

Caffeic, ferulic, p-coumaric, protocatechuic, syringic, rosmarinic, p-hydroxybenzoic and chlorogenic acid, quercetin, catechin, epicatechin, ABTS: 2,2'azino-bis(3-ethylbenzothiazoline-6-sulfonic acid), Trolox: ( \pm -6-hydroxy-2,5,7,8-tetramethylchromane-2-carboxylic acid (97\%), anhydrous sodium acetate, Folin-Ciocalteu's (F-C) (2N), sodium carbonate and manganese dioxide were purchased from Sigma (Madrid, Spain). DPPH: 2,2-diphenyl-1-picrylhydrazyl from Extrasynthèse (Genay, France). Acetonitrile, ethanol and methanol and formic acid $(\geq 98 \%)$ were acquired from Scharlau (Barcelona, Spain). Ultrapure water was obtained from a Milli-Q Gradient water purification system (Millipore Bedford, MA, USA). Samples were stored at $4{ }^{\circ} \mathrm{C}$ and protected from light before analysis.

\subsection{Plant material and sample preparation}

Ground dried dill (Anethum graveolens), marjoram (Origanum majorana), turmeric (Curcuma longa), caraway (Carum carvi), and nutmeg (Myristica fragans) were sourced from Nutreco Research and Development (Boxmeer, The Netherlands). Plant materials were extracted with a hydroalcoholic solvent. Afterwards, the extracted sample was centrifuged and dried. The dried spices were ground $(500-600 \mu \mathrm{m})$ and stored at $-20^{\circ} \mathrm{C}$ in darkness.

Each sample was divided into 3 aliquots and each extracted twice in a darkened room equipped with a red safety light to prevent photodegradation of the analytes following a previously reported procedure with minor modifications (Vallverdú-Queralt et al., 2011a). Briefly, sample aliquots $(1 \mathrm{~g})$ were extracted with $5 \mathrm{~mL}$ of $50 \%$ ethanol in ultrapure water containing $0.1 \%$ formic acid, sonicated for $5 \mathrm{~min}$ and centrifuged at $3,000 \mathrm{x}$ g for $10 \mathrm{~min}$ at $4{ }^{\circ} \mathrm{C}$. The extraction procedure was repeated twice with the plant material residue. Both supernatants were combined and the organic solvent was evaporated under nitrogen flow. Finally, extracts were reconstituted up to $5 \mathrm{~mL}$ with $0.1 \%$ formic acid in water.

A solid-phase extraction (SPE) procedure was carried out to eliminate potential interferences from plant extracts. Oasis MAX mixed-mode anion-exchange cartridges (96-well plates, $30 \mathrm{mg}, 30 \mu \mathrm{m}$ ) from Waters (Milford, USA) were used following a previously developed procedure (Vallverdú-Queralt et al., 2012).

\subsection{HPLC-MS analysis}

For accurate-mass measurements, a LTQ Orbitrap Velos mass spectrometer (Thermo Fischer Scientific, Hemel Hempstead, UK) equipped with an ESI source was used, operating in negative mode. Plant extracts were first analyzed in full scan (MS) mode at a resolution of 60,000 (at $m / z 400$ ). The successive analyses were done in MS/MS mode with the Orbitrap resolution set at 30,000 (at $\mathrm{m} / z$ 400). The most intense ions detected in the full scan spectrum were selected for the data-dependent scan. Instrument control and data acquisition were performed with Xcalibur 2.0.7 software (Thermo Fisher Scientific). An external calibration for mass accuracy was carried out the day before the analysis according to the manufacturer's guidelines.

Chromatographic separation was carried out in a HPLC system Accela (Thermo Fischer Scientific) equipped with a quaternary pump, a photodiode array detector (PDA) and a thermostatted autosampler. A reversed-phase column Atlantis T3 C18 $(100 \times 2.1 \mathrm{~mm}, 3 \mu \mathrm{m})$ from Waters was used, maintained at $25^{\circ} \mathrm{C}$. Mobile phases A and B were $0.1 \%$ formic acid in water and $0.1 \%$ formic acid in acetonitrile, respectively. The following linear gradient was used: $0 \mathrm{~min}, 10 \% \mathrm{~B} ; 1 \mathrm{~min}, 10 \% \mathrm{~B} ; 15 \mathrm{~min}$, $30 \%$ B; 22 min, $50 \%$ B; 28 min, 100\% B; 34 min, 100\% B, 36 min, $10 \% \mathrm{~B}$. The column was equilibrated for 6 min prior to analysis. The flow rate was set to $350 \mu \mathrm{L} / \mathrm{min}$ and the injection volume was $5 \mu \mathrm{L}$. These conditions were adapted from a previous work with some modifications (Vallverdú-Queralt et al., 2013a).

Quantification of the previously identified compounds was performed by HPLC-ESI-MS/MS using an Agilent series 1100 HPLC system (Agilent, Waldbronn, Germany) coupled to an API 3000 triple quadrupole mass spectrometer (PE Sciex, Concord, Ontario, Canada) equipped with a Turbo Ionspray source, operated in negative ion mode. Separation was carried out under the same chromatographic conditions used during the identification step.

Ethyl gallate was used as internal standard in order to improve the precision of quantitative analysis; results were expressed as $\mu \mathrm{g} / \mathrm{g}$ dry weight (DW).

\subsection{Total polyphenols content}

For the total polyphenol (TP) assay, each sample was analyzed in triplicate; $20 \mu \mathrm{L}$ of the eluted fractions from the SPE were mixed with $188 \mu \mathrm{L}$ of Milli-Q water in a thermo microtiter 96-well plate (Nunc, Roskilde, Denmark), and $12 \mu \mathrm{L}$ of Folin-Ciocalteau's $(\mathrm{F}-\mathrm{C})$ reagent $(2 \mathrm{~N})$ and $30 \mu \mathrm{L}$ of sodium carbonate $(200 \mathrm{~g} / \mathrm{L})$ were added following the procedure described by other authors (Vallverdu-Queralt et al 2013b). Results were expressed as mg of gallic acid equivalents (GAE)/g DW.

\subsection{Antioxidant capacity}

The culinary herb and spice extracts prepared for polyphenol analysis were also analyzed for their antioxidant capacity (AC). The $\mathrm{AC}$ was measured using an $\mathrm{ABTS}^{+}$radical decolorization assay and DPPH assay (Vallverdú-Queralt et al., 2014). 


\subsection{Statistical analysis}

The significance of the results and statistical differences were analyzed using Statgraphics plus v. 5.1 software (Manugistics, Inc., Rockville, MA, USA). Data were analyzed by multifactor analysis of variance and a Duncan multiple range test was applied to determine differences among means, with a significance level of $p=0.05$. The multivariate analyses were the Principal Component Analysis (PCA) and Hierarchical Cluster Analysis (HCA) using the Euclidean distance as distance measurement and Ward's as the aggregation method. Such multivariate analyses were carried out to evaluate the influence of polyphenol compounds in the classification and differentiation of herb and spice samples.

\section{Results and discussion}

\subsection{Total phenol content and antioxidant activity}

Culinary herbs and spices are attracting growing interest due to their content of phenolic compounds that may exert beneficial effects on human health. The content of TP and antioxidant capacity of the studied herbs and species are presented in Table 1. TP content ranged from $0.43 \mathrm{mg} \mathrm{GAE} / \mathrm{g}$ DW in turmeric to $3.99 \mathrm{mg} \mathrm{GAE} / \mathrm{g} \mathrm{DW}$ in caraway. AC according to the ABTS+ assay ranged between $0.27 \mathrm{mmol} \mathrm{TE} / \mathrm{g} \mathrm{DW}$ and $2.32 \mathrm{mmol}$ TE/g DW in turmeric and caraway, respectively, and according to the DPPH assay between $0.11 \mathrm{mmol} \mathrm{TE} / \mathrm{g} \mathrm{DW}$ and $1.63 \mathrm{mmol} \mathrm{TE} / \mathrm{g} \mathrm{DW}$, respectively.

Significant differences in AC was found in the order of caraway $>$ marjoram $>$ dill $>$ nutmeg $>$ turmeric $(p<0.05)$. TP content showed a good correlation with the AC assays: ABTS $+\left(\mathrm{R}^{2}=0.9807, p<0.01\right)$ and DPPH $\left(\mathrm{R}^{2}=0.9973, p<0.01\right)$. $\mathrm{AC}$ of other herbs and spices extracts such as oregano, rosemary, cumin, sage, fennel and thyme have been studied in different model systems (Hinneburg et al., 2006; Erkan et al., 2008; Vichi et al., 2001). Rosemary and sage have been reported to be particularly effective antioxidants, and oregano, thyme, turmeric, and nutmeg have also shown a high AC in both ground and extract form (Kähkönen et al., 1999).

\subsection{Characterization of phenolic compounds by HPLC-LTQ-Orbitrap-MS}

Combining high-resolution accurate-mass measurement and multistage mass spectrometry $\left(\mathrm{MS}^{\mathrm{n}}\right)$ increased the confidence in the identification. The MS/MS spectra were compared with those

Table 1. Total Polyphenols (mg EAG /g DW) and Hydrophilic antioxidant capacity of Eastern culinary herbs and spices measured by ABTS+ and $\mathrm{DPPH}$ assays ( $\mathrm{mmol} \mathrm{TE} / \mathrm{g} \mathrm{DW}$ ) expressed as mean $\pm \mathrm{SD}$. Different letters in the columns represent Statistically Significant Differences $(P<0.05)$.

\begin{tabular}{cccc}
\hline Herbs/ Spices & TP & ABTS $^{+}$ & DPPH \\
\hline Caraway & $3.99 \pm 0.44$ & $2.32 \pm 0.24$ & $1.63 \pm 0.07$ \\
Turmeric & $0.43 \pm 0.04$ & $0.27 \pm 0.01$ & $0.11 \pm 0.01$ \\
Dill & $0.94 \pm 0.04$ & $0.74 \pm 0.04$ & $0.27 \pm 0.01$ \\
Marjoram & $0.96 \pm 0.09$ & $0.84 \pm 0.07$ & $0.33 \pm 0.02$ \\
Nutmeg & $0.63 \pm 0.09$ & $0.42 \pm 0.04$ & $0.12 \pm 0.01$ \\
\hline
\end{tabular}

EAG: Equivalents of Gallic Acid; TE: Trolox equivalents; SD: standard deviation. of candidate compounds found in previous literature, especially when the presence of the compound was reported in any of the studied plants. Identified compounds were then positively confirmed by comparing their retention times and accurate masses with those of commercial standards when available.

Under these conditions, a total of 42 phenolic compounds could be identified among the different studied herbs and spices. Corresponding molecular formulas, their MS/MS fragments, mass measurement errors $(\Delta \mathrm{m})$ and retention times $\left(t_{R}\right)$ are shown in Table 2.

To the best of our knowledge, two of the identified polyphenols in this work, apigenin- $C$-hexoside- $C$-hexoside $(\mathrm{m} / z 593)$ and apigenin- $C$-hexoside- $C$-pentoside $(\mathrm{m} / z 563)$, are reported for the first time in turmeric extracts. Thus, while apigenin- $C$-hexoside- $C$-hexoside has been previously found in marjoram (Kaiser et al., 2013), it has not been hitherto detected in turmeric. Based on MS/MS spectra previously reported by Vallverdú-Queralt et al. (2014), apigenin- $C$-hexoside- $C$-hexoside and apigenin- $C$-hexoside- $C$-pentoside were distinguished by the presence of the ion [M-H-60]- Fragmentation of $m / z 593$ produced ions at $m / z 503$ [M-H-90]', 473 [M-H-120] ${ }^{-}$and 353 [M-H-120-120]', while the ion of [M-H-60] ' was absent, whereas MS/MS of $m / z 563$ yielded the ions at $m / z 503$ [M-H-60]', 473 [M-H-90]', 383 [M-H-90-90] and 353 [M-H-90-120]', suggesting the presence of a pentose substitution.

Protocatechuic $(m / z 153)$, caffeic $(m / z 179)$, neochlorogenic, cryptochlorogenic and chlorogenic $(m / z 353)$, rosmarinic $(m / z 359)$, ferulic $(m / z 193)$, $p$-coumaric $(\mathrm{m} / \mathrm{z} 163)$, syringic $(m / z 197)$, gallic $(m / z 169), p$ - and $m$-hydroxybenzoic $(m / z 137)$ acids and kaempferol-3-O-glucoside $(m / z 447)$, kaempferol $(m / z 285)$ and quercetin $(\mathrm{m} / z$ 301) were detected in all the culinary herbs and spices. Several trimeric proanthocyanidins $(\mathrm{m} / z$ 863) and one hexamer $(m / z$ 1727) were also detected in caraway. The hexamers and trimers found in this study were A-type oligomers, which are structural variations of proanthocyanidin oligomers, with the formation of a second interflavanoid bond by $C$ - $O$ oxidative coupling. The most common classes of proanthocyanidins consist of subunits of catechin, epicatechin, and their gallic acid esters (B-type oligomers) (Lazarus et al., 1999). The proanthocyanidin hexamer showed doubly charged ions at $m / z 863$ corresponding to a monoisotopic ion at $m / z 1727.3730$. The $[\mathrm{M}-2 \mathrm{H}]^{2-}$ ion was confirmed by the $0.5 \mathrm{Da}$ mass differences between the isotopic peaks.

\subsection{Quantification of phenolic compounds by HPLC-QqQ-MS/MS}

Once the identities of the major phenolic compounds had been established, their quantitative analysis in the different herbs and spices was carried. The concentration of individual polyphenols in caraway, turmeric, dill, marjoram and nutmeg are shown in Figure 1. Individual polyphenol content was highest in caraway (about $65 \mu \mathrm{g} / \mathrm{g}$ DW), followed by dill (approximately $35 \mu \mathrm{g} / \mathrm{g}$ DW) and lowest in turmeric (below $10 \mu \mathrm{g} / \mathrm{g}$ DW). These data are in agreement with the obtained AC and TP values.

As can be seen, the major phenolic acid in caraway (14.14 g/g DW) and dill (20.20 $\mu \mathrm{g} / \mathrm{g}$ DW) was chlorogenic acid 
Table 2. List of compounds identified in Eastern culinary herbs and spices

\begin{tabular}{|c|c|c|c|c|c|c|c|}
\hline Compound & Herb & $\mathrm{rt}$ & {$[\mathrm{M}-\mathrm{H}]-$} & $\begin{array}{c}\text { MS/MS ions } \\
\text { (\% relative abundance) }\end{array}$ & Acc Mass & $\mathrm{mDa}$ & MF \\
\hline Syringic acid ${ }^{*}$ & $\mathrm{C}, \mathrm{D}, \mathrm{M}, \mathrm{N}, \mathrm{T}$ & 1.70 & 197 & $182(40), 167(40)$ & 197.0455 & 0.5 & $\mathrm{C} 9 \mathrm{H} 10 \mathrm{O} 5$ \\
\hline Neochlorogenic acid & $\mathrm{C}, \mathrm{D}, \mathrm{M}, \mathrm{N}, \mathrm{T}$ & 2.13 & 353 & $191(100), 179(40), 135(20)$ & 353.0877 & 0.8 & $\mathrm{C} 16 \mathrm{H} 18 \mathrm{O} 9$ \\
\hline Protocatechuic acid ${ }^{*}$ & $\mathrm{C}, \mathrm{D}, \mathrm{M}, \mathrm{N}, \mathrm{T}$ & 2.36 & 153 & $153(40), 109(90)$ & 153.0193 & 0.4 & C7H6O4 \\
\hline Homovanillic acid-O-hexoside & $\mathrm{T}$ & 3.14 & 343 & $181(100), 137(10)$ & 343.1034 & 0.7 & $\mathrm{C} 15 \mathrm{H} 20 \mathrm{O} 9$ \\
\hline 3-O-p-coumaroylqunic acid & $\mathrm{C}, \mathrm{D}, \mathrm{N}, \mathrm{T}$ & 3.29 & 337 & $191(10), 163(100)$ & 337.0930 & 1.5 & $\mathrm{C} 16 \mathrm{H} 18 \mathrm{O} 8$ \\
\hline Caffeic acid- $O$-hexoside 3 & C,D & 3.30 & 341 & $179(100)$ & 341.0877 & 0.7 & $\mathrm{C} 15 \mathrm{H} 18 \mathrm{O} 9$ \\
\hline p-hydroxybenzoic acid ${ }^{*}$ & $\mathrm{C}, \mathrm{D}, \mathrm{M}, \mathrm{N}, \mathrm{T}$ & 3.52 & 137 & $93(100)$ & 137.0244 & 0.4 & $\mathrm{C} 7 \mathrm{H} 6 \mathrm{O} 3$ \\
\hline Chlorogenic acid ${ }^{*}$ & $\mathrm{C}, \mathrm{D}, \mathrm{M}, \mathrm{N}, \mathrm{T}$ & 3.58 & 353 & $191(100)$ & 353.0877 & 0.9 & $\mathrm{C} 16 \mathrm{H} 18 \mathrm{O} 9$ \\
\hline Proanthocyanidin trimer 1 & C & 4.65 & 863 & $711(60), 575$ (100), $287(10)$ & 863.1829 & 1.5 & $\mathrm{C} 45 \mathrm{H} 36 \mathrm{O} 18$ \\
\hline Caffeic acid* & $\mathrm{C}, \mathrm{D}, \mathrm{M}, \mathrm{N}, \mathrm{T}$ & 4.84 & 179 & $135(100)$ & 179.0349 & 0.3 & $\mathrm{C} 9 \mathrm{H} 8 \mathrm{O} 4$ \\
\hline Proanthocyanidin trimer 2 & C & 5.02 & 863 & $711(60), 575(100), 287(10)$ & 863.1829 & 1.3 & $\mathrm{C} 45 \mathrm{H} 36 \mathrm{O} 18$ \\
\hline Epicatechin ${ }^{\star}$ & $\mathrm{C}$ & 5.32 & 289 & $245(100)$ & 289.0718 & 1.3 & $\mathrm{C} 15 \mathrm{H} 14 \mathrm{O} 6$ \\
\hline Apigenin- $C$-hexoside- $C$-hexoside & $\mathrm{T}$ & 5.36 & 593 & $503(30), 473$ (100), $383(20), 353(40)$ & 593.1511 & 0.7 & $\mathrm{C} 27 \mathrm{H} 30 \mathrm{O} 15$ \\
\hline 4-O-p-coumaroylqunic acid & $\mathrm{C}, \mathrm{D}, \mathrm{N}$ & 5.67 & 337 & $191(20), 173(100), 163(30)$ & 337.0930 & 0.1 & $\mathrm{C} 16 \mathrm{H} 18 \mathrm{O} 8$ \\
\hline Ferulic acid- $O$-hexoside & $\mathrm{T}$ & 5.78 & 355 & $193(100)$ & 355.1034 & 0.9 & $\mathrm{C} 16 \mathrm{H} 20 \mathrm{O} 9$ \\
\hline Vanillic acid & $\mathrm{C}, \mathrm{M}, \mathrm{N}, \mathrm{T}$ & 7.03 & 167 & $167(50), 152(20), 108(50)$ & 167.0350 & 0.4 & $\mathrm{C} 8 \mathrm{H} 8 \mathrm{O} 4$ \\
\hline Apigenin- $C$-hexoside-C-pentoside & $\mathbf{T}$ & 7,78 & 563 & $503(10), 473$ (25), 383 (15), 353 (25) & 563,1406 & 0,90 & $\mathrm{C}_{26} \mathrm{H}_{28} \mathrm{O}_{14}$ \\
\hline Proanthocyanidin trimer 3 & C & 7.48 & 863 & $711(60), 575(100), 287(10)$ & 863.1829 & 1.8 & $\mathrm{C} 45 \mathrm{H} 36 \mathrm{O} 18$ \\
\hline Hesperidin ${ }^{\star}$ & $\mathrm{D}, \mathrm{N}, \mathrm{T}$ & 10.91 & 609 & $301(100)$ & 609.1825 & 0.9 & C28H34015 \\
\hline Apigenin-7-O-glucoside ${ }^{*}$ & $\mathrm{~N}, \mathrm{~T}$ & 10.93 & 431 & $269(100)$ & 431.0983 & 1.1 & $\mathrm{C} 21 \mathrm{H} 20 \mathrm{O} 10$ \\
\hline Rosmarinic acid $^{*}$ & $\mathrm{C}, \mathrm{D}, \mathrm{M}, \mathrm{N}, \mathrm{T}$ & 12.05 & 359 & $197(30), 161(100)$ & 359.0772 & 1.1 & $\mathrm{C} 18 \mathrm{H} 16 \mathrm{O} 8$ \\
\hline Narigenin- $O$-hexoside & $\mathbf{M}, \mathbf{T}$ & 12.90 & 433 & $271(100)$ & 433.1140 & 1.4 & $\mathrm{C} 21 \mathrm{H} 22 \mathrm{O} 10$ \\
\hline Eriodictyol & $\mathbf{M}, \mathbf{N}$ & 15.10 & 287 & $287(15), 151(100)$ & 287,0560 & 0.2 & $\mathrm{C} 15 \mathrm{H} 12 \mathrm{O} 6$ \\
\hline Kaempferol $^{*}$ & $\mathrm{C}, \mathrm{D}, \mathrm{M}, \mathrm{N}, \mathrm{T}$ & 15.24 & 285 & $285(40), 151(100)$ & 285.0405 & 0.9 & C15H10O6 \\
\hline Quercetin* & $\mathrm{C}, \mathrm{D}, \mathrm{M}, \mathrm{N}, \mathrm{T}$ & 15.33 & 301 & $301(10), 151(100)$ & 301.0353 & 0.5 & $\mathrm{C} 15 \mathrm{H} 10 \mathrm{O} 7$ \\
\hline Naringenin ${ }^{*}$ & $\mathbf{M}, \mathbf{N}, \mathbf{T}$ & 17.40 & 271 & $271(15), 151(100)$ & 271.0611 & 1.1 & $\mathrm{C} 15 \mathrm{H} 12 \mathrm{O} 5$ \\
\hline Apigenin ${ }^{*}$ & $\mathbf{N}, \mathbf{T}$ & 17.55 & 269 & $269(10), 151(100)$ & 269.0455 & 0.6 & $\mathrm{C} 15 \mathrm{H} 10 \mathrm{O} 5$ \\
\hline Hesperetin* & $\mathrm{C}, \mathrm{D}, \mathrm{N}, \mathrm{T}$ & 17.91 & 301 & $286(30), 151(100)$ & 301.0718 & 1.2 & $\mathrm{C} 16 \mathrm{H} 14 \mathrm{O} 6$ \\
\hline
\end{tabular}

C: Caraway; D: Dill; M: Marjoram; N: Nutmeg; T: Turmeric. ${ }^{*}$ Comparison with standard.

(Figure 1), which is one of the principle phenolic compounds found in most herbs and spices, together with $p$-coumaric and p-hydroxybenzoic acids (Shan et al., 2005). A similar pattern was observed for $p$-coumaric and caffeic acid, with the highest levels found in caraway (10.62 and $10.02 \mu \mathrm{g} / \mathrm{g} \mathrm{DW}$, respectively) and the lowest in marjoram $(0.16 \mu \mathrm{g} / \mathrm{g}$ DW caffeic acid $)$ and turmeric (1.05 $\mu \mathrm{g} / \mathrm{g}$ DW $p$-coumaric acid). These results are in accordance with Shan et al. (2005), who detected caffeic acid in caraway, although they did not report $p$-coumaric acid in caraway or in dill. Caffeic acid has also been previously identified in oregano, marjoram and rosemary (Herrero et al., 2010; Agiomyrgianaki \& Dais, 2012; Papageorgiou et al., 2008). In another study investigating the phenolic content of 26 common herb and spice extracts from 12 botanical families, caffeic acid was detected in caraway $(16.4 \mathrm{mg} / 100 \mathrm{~g} \mathrm{DW})$ and nutmeg (16.3 mg/100g DW), respectively, but not in dill (Shan et al., 


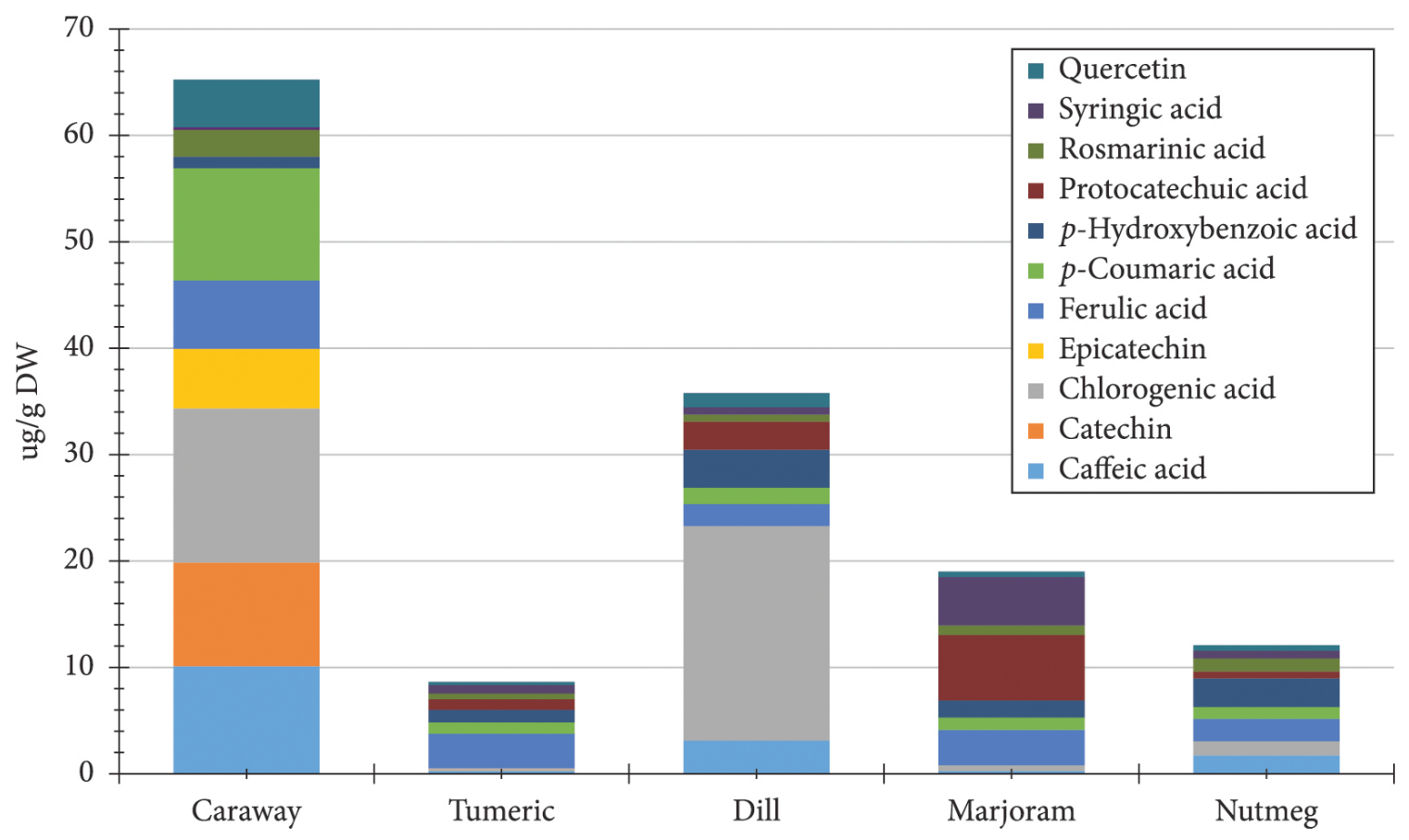

Figure 1. Quantification of individual polyphenols in the studied herbs and spices expressed as $\mu \mathrm{g} / \mathrm{g}$ DW.

2005). Differences among phenolic acid levels in the literature can be attributed to genotypic and environmental variation within species, choice of plant parts tested, when samples were taken and determination methods.

Ferulic acid showed the same pattern as the aforementioned phenolic acids, with caraway containing the highest amount $(6.42 \mu \mathrm{g} / \mathrm{g} \mathrm{DW})$, followed by marjoram $(3.37 \mu \mathrm{g} / \mathrm{g} \mathrm{DW})$, while dill showed the lowest levels $(2.07 \mu \mathrm{g} / \mathrm{g}$ DW $)$. These levels of ferulic acid were lower than those of another study on marjoram (Baâtour et al., 2012), which ranged between $6.39 \mu \mathrm{g} / \mathrm{g}$ DW and $37.57 \mu \mathrm{g} / \mathrm{g}$ DW.

The highest levels of protocatechuic acid were found in marjoram $(6.17 \mu \mathrm{g} / \mathrm{g} \mathrm{DW})$ and the lowest in nutmeg $(0.58 \mu \mathrm{g} / \mathrm{g}$ DW). Shan et al. (2005) detected protocatechuic acid in sweet basil, dill, star anise and coriander, but not in caraway and nutmeg, while other results in the literature show that protocatechuic acid is not always present in marjoram and turmeric (Papageorgiou et al., 2008; Baâtour et al., 2012). We also found the highest syringic acid levels in marjoram ( $4.62 \mu \mathrm{g} / \mathrm{g} \mathrm{DW})$, where it has been detected previously (Baâtour et al., 2012). Kivilompolo et al. (2007) found less than $50 \mu \mathrm{g} / \mathrm{g}$ DW syringic acid in thyme, with undetectable levels in the other herb extracts analyzed. In contrast, Hossain et al. (2010) reported the presence of syringic acid in thyme, rosemary, oregano and bay.

Rosmarinic acid levels were highest in caraway $(2.50 \mu \mathrm{g} / \mathrm{g} \mathrm{DW})$ and nutmeg $(1.29 \mu \mathrm{g} / \mathrm{g} \mathrm{DW})$ and lowest in dill $(0.52 \mu \mathrm{g} / \mathrm{g} \mathrm{DW})$. Rosmarinic acid has been previously detected in mint, sweet basil, oregano, rosemary, sage, thyme and marjoram, but not in nutmeg, dill, caraway and turmeric (Shan et al., 2005; Sellami et al., 2009). Rosmarinic acid has proven potent antioxidant activities, as do other compounds present in rosemary (e.g. carnosol, rosmanol, and epi-rosmanol), and is well correlated with total antioxidant activity (Herrero et al., 2010). p-hydroxybenzoic acid was detected in all the herbs and spices, but the amount found in dill $(3.55 \mu \mathrm{g} / \mathrm{g}$ DW $)$ or nutmeg $(2.70 \mu \mathrm{g} / \mathrm{g} \mathrm{DW})$ was higher than in caraway $(1.07 \mu \mathrm{g} / \mathrm{g}$ DW) or turmeric $(1.17 \mu \mathrm{g} / \mathrm{g} D W)$.

Catechin and epicatechin were only found in caraway $(9.78 \pm 0.39 \mu \mathrm{g} / \mathrm{g}$ DW and $5.62 \pm 0.42 \mu \mathrm{g} / \mathrm{g}$ DW, respectively), being under the detection limits in the other studied plant products. Baâtour et al. (2012) reported both phenolic compounds in marjoram (7.2-177 $\mu \mathrm{g} / \mathrm{g}$ DW catechin and 51-78 $\mu \mathrm{g} / \mathrm{g} \mathrm{DW}$ epicatechin). In contrast to our results, Shan et al. (2005) identified catechin in dill, sage, rosemary, mint and cinnamon but not in caraway.

Lastly, quercetin was detected and quantified in all the studied herbs and spices, with levels ranging from $0.33 \mu \mathrm{g} / \mathrm{g} \mathrm{DW}$ in turmeric to $4.52 \mu \mathrm{g} / \mathrm{g} \mathrm{DW}$ in caraway. Quercetin has been previously detected in rosemary, oregano, sage, bay, thyme (Hossain et al., 2010) and marjoram (Baâtour et al., 2012), but not in nutmeg, dill, caraway and turmeric (Shan et al., 2005).

\subsection{Multivariate analyses}

A multiparametric approach with both HCA and PCA was carried out in order to assess whether the differences in their phenolic composition enable to differentiate and to properly classify the studied herb/spice samples.

A data matrix containing all the information regarding the concentrations of each phenolic compound in every sample was subjected to a HCA, taking the Euclidean distance as metric and Ward's method as the agglomeration rule. Cluster analysis is an exploratory data analysis tool which aims at sorting different 
objects into groups in a way that the similarity between two objects is maximal if they belong to the same group and minimal otherwise. The results of the cluster analysis are displayed as a dendrogram in Figure 2. From the bottom up, the dendrogram shows the sequence of joins that were made between clusters. Lines are drawn connecting the clustered that are joined at each step, while the vertical axis displays the distance between the clusters when they were joined. Two main clusters can be observed, one for caraway and the other for turmeric, nutmeg, dill and marjoram. This separation could be expected due to the high phenolic content of caraway. Additionally, marjoram is clearly differentiated from dill, turmeric and nutmeg, while turmeric and nutmeg are shown to have few differences.

Regarding the PCA analysis, its main goal is to reduce a large set of variables to a small set that still contains most of the information in the large set. In the PCA, two principal components (PC1 and PC2) were sufficient to account for $85.19 \%$ of the total variance of the original data. It can be clearly observed that syringic and protocatechuic acid are highly correlated with marjoram (Figure 3). In contrast, caraway, which is situated at the other side of the plot, is related to lower levels of these metabolites and higher levels of ferulic, rosmarinic, $p$-coumaric and caffeic acids and quercetin, catechin and epicatechin. On the left-hand

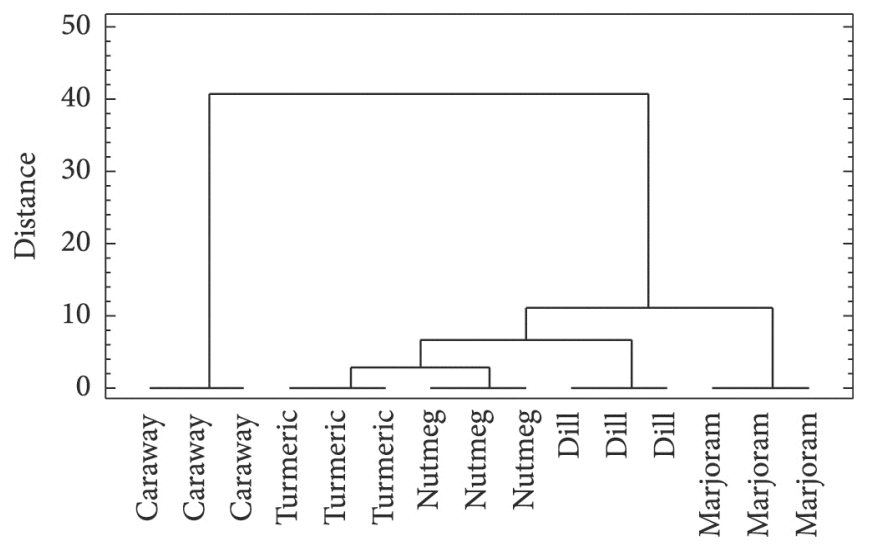

Figure 2. Dendogram obtained after hierarchical cluster analysis of individual polyphenols in the studied herbs and spices.

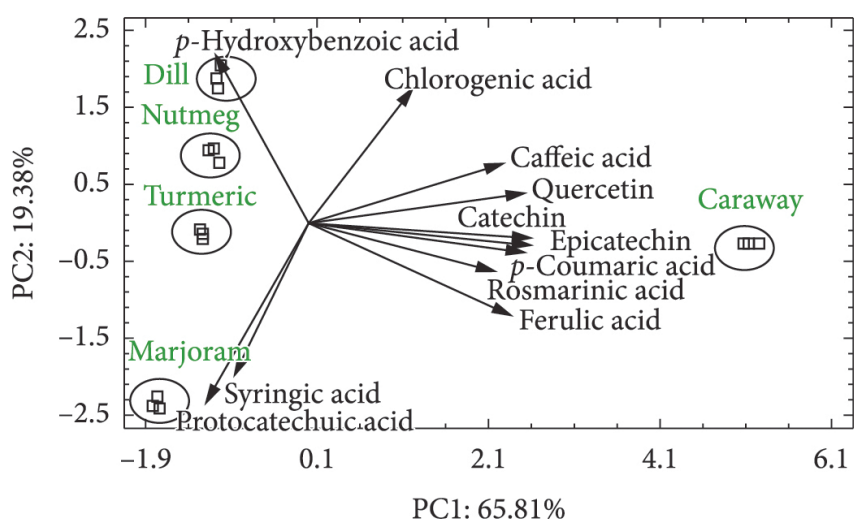

Figure 3. Biplot of samples representing the polyphenol profile of the studied culinary herbs and spices. side of the plot, turmeric and nutmeg are slightly correlated with ferulic, rosmarinic, $p$-coumaric and caffeic acids and quercetin, catechin and epicatechin. Lastly, dill is highly correlated with $p$-hydroxybenzoic and chlorogenic acids.

\section{Conclusions}

The use of HPLC coupled to LTQ-Orbitrap mass spectrometry was demonstrated as a powerful tool for the characterization of phenolic compounds in caraway, turmeric, dill, marjoram and nutmeg. The availability of the molecular formulas estimated from high-resolution/accurate-mass measurements along with the MS/MS fragmentation pattern allowed to speed up the identification process and to provide a higher degree of confidence.

Among the 42 identified phenolic compounds, apigenin- $C$-hexoside- $C$-hexoside and apigenin- $C$-hexoside- $C$-pentoside, as far as we know, have been identified for the first time in turmeric extracts.

After quantification of the individual phenolic compounds, multivariate analysis revealed distinguishing features among the studied herbs and spices. Caraway exhibited both the highest antioxidant activity and the highest content of polyphenols. Further research concerning the bioavailability of these polyphenols in epidemiological or clinical intervention studies needs to be carried out. These culinary ingredients have considerable potential as health-promoting products due to their bioactive phytochemicals.

\section{Acknowledgements}

Funding for this work was provided by CICYT (AGL2010-22319-C03; AGL2013-49083-C3-1-R) and the Instituto de Salud Carlos III, ISCIII (CIBEROBN) from the Spanish Ministry of Science and Innovation Ministerio de Ciencia e Innovación (MICINN) and Quality Group from Generalitat de Catalunya Generalitat de Catalunya (GC) 2014 SGR 773. A.V.-Q thanks the postdoctoral fellowship from the Foundation Alfonso Martín Escudero for carrying out research in foreign countries.

\section{References}

Agiomyrgianaki, A., \& Dais, P. (2012). Simultaneous determination of phenolic compounds and triterpenic acids in oregano growing wild in Greece by 31P NMR spectroscopy. Magnetic Resonance in Chemistry, 50(11), 739-748. http://dx.doi.org/10.1002/mrc.3877. PMid:23001915

Amarowicz, R., Żegarska, Z., Rafałowski, R., Pegg, R. B., Karamać, M., \& Kosińska, A. (2009). Antioxidant activity and free radicalscavenging capacity of ethanolic extracts of thyme, oregano, and marjoram. European Journal of Lipid Science and Technology, 111(11), 1111-1117. http://dx.doi.org/10.1002/ejlt.200800170.

Baâtour, O., Kaddour, R., Tarchoun, I., Nasri, N., Mahmoudi, H., Zaghdoudi, M., Ghaith, H., Marzouk, B., Ben Nasri-Ayachi, M., \& Lachaâl, M. (2012). Modification of fatty acid, essential oil and phenolic contents of salt-treated sweet marjoram (Origanum majorana L.) according to developmental stage. Journal of Food Science, 77(10), C1047-C1054. http://dx.doi.org/10.1111/j.17503841.2012.02904.x. PMid:22978424 
Erkan, N., Ayranci, G., \& Ayranci, E. (2008). Antioxidant activities of rosemary (Rosmarinus Officinalis L.) extract, blackseed (Nigella sativa L.) essential oil, carnosic acid, rosmarinic acid and sesamol. Food Chemistry, 110(1), 76-82. http://dx.doi.org/10.1016/j. foodchem.2008.01.058.

Halvorsen, B. L., Holte, K., Myhrstad, M. C., Barikmo, I., Hvattum, E., Remberg, S. F., Wold, A. B., Haffner, K., Baugerød, H., Andersen, L. F., Moskaug, Ø., Jacobs, D. R. Jr., \& Blomhoff, R. (2002). A systematic screening of total antioxidants in dietary plants. The Journal of Nutrition, 132(3), 461-471. PMid:11880572.

Herrero, M., Plaza, M., Cifuentes, A., \& Ibáñez, E. (2010). Green processes for the extraction of bioactives from Rosemary: Chemical and functional characterization via ultra-performance liquid chromatography-tandem mass spectrometry and in-vitro assays. Journal of Chromatography. A, 1217(16), 2512-2520. http://dx.doi. org/10.1016/j.chroma.2009.11.032. PMid:19945706

Hinneburg, I., Damien Dorman, H. J., \& Hiltunen, R. (2006). Antioxidant activities of extracts from selected culinary herbs and spices. Food Chemistry, 97(1), 122-129. http://dx.doi.org/10.1016/j. foodchem.2005.03.028.

Hossain, M. B., Rai, D. K., Brunton, N. P., Martin-Diana, A. B., \& Barry-Ryan, C. (2010). Characterization of phenolic composition in Lamiaceae spices by LC-ESI-MS/MS. Journal of Agricultural and Food Chemistry, 58(19), 10576-10581. http://dx.doi.org/10.1021/ jf102042g. PMid:20825192

Kähkönen, M. P., Hopia, A. I., Vuorela, H. J., Rauha, J. P., Pihlaja, K., Kujala, T. S., \& Heinonen, M. (1999). Antioxidant activity of plant extracts containing phenolic compounds. Journal of Agricultural and Food Chemistry, 47(10), 3954-3962. http://dx.doi.org/10.1021/ jf990146l. PMid:10552749

Kaiser, A., Carle, R., \& Kammerer, D. R. (2013). Effects of blanching on polyphenol stability of innovative paste-like parsley (Petroselinum crispum (Mill.) Nym ex A. W. Hill) and marjoram (Origanum majorana L.) products. Food Chemistry, 138(2-3), 1648-1656. http:// dx.doi.org/10.1016/j.foodchem.2012.11.063. PMid:23411294

Kivilompolo, M., Obůrka, V., \& Hyötyläinen, T. (2007). Comparison of GC-MS and LC-MS methods for the analysis of antioxidant phenolic acids in herbs. Analytical and Bioanalytical Chemistry, 388(4), 881887. http://dx.doi.org/10.1007/s00216-007-1298-8. PMid:17468851

Lazarus, S. A., Adamson, G. E., Hammerstone, J. F., \& Schmitz, H. H. (1999). High-performance liquid Chromatography/Mass spectrometry analysis of proanthocyanidins in foods and beverages. Journal of Agricultural and Food Chemistry, 47(9), 3693-3701. http://dx.doi. org/10.1021/jf9813642. PMid:10552707

Papageorgiou, V., Mallouchos, A., \& Komaitis, M. (2008). Investigation of the antioxidant behavior of air- and freeze-dried aromatic plant materials in relation to their phenolic content and vegetative cycle. Journal of Agricultural and Food Chemistry, 56(14), 5743-5752. http://dx.doi.org/10.1021/jf8009393. PMid:18578534

Park, J. B. (2011). Identification and quantification of a major anti-oxidant and anti-inflammatory phenolic compound found in basil, lemon thyme, mint, oregano, rosemary, sage, and thyme. International Journal of Food Sciences and Nutrition, 62(6), 577-584. http://dx.doi. org/10.3109/09637486.2011.562882. PMid:21506887
Regueiro, J., Sánchez-González, C., Vallverdú-Queralt, A., SimalGándara, J., Lamuela-Raventós, R., \& Izquierdo-Pulido, M. (2014). Comprehensive identification of walnut polyphenols by liquid chromatography coupled to linear ion trap-Orbitrap mass spectrometry. Food Chemistry, 152, 340-348. http://dx.doi. org/10.1016/j.foodchem.2013.11.158. PMid:24444946

Sellami, I. H., Maamouri, E., Chahed, T., Wannes, W. A., Kchouk, M. E., \& Marzouk, B. (2009). Effect of growth stage on the content and composition of the essential oil and phenolic fraction of sweet marjoram (Origanum majorana L.). Industrial Crops and Products, 30(3), 395-402. http://dx.doi.org/10.1016/j.indcrop.2009.07.010.

Shan, B., Cai, Y. Z., Sun, M., \& Corke, H. (2005). Antioxidant capacity of 26 spice extracts and characterization of their phenolic constituents. Journal of Agricultural and Food Chemistry, 53(20), 7749-7759. http://dx.doi.org/10.1021/jf051513y. PMid:16190627

Shobana, S., \& Naidu, K. A. (2000). Antioxidant activity of selected Indian spices. Prostaglandins Leukot Essent Fatty Acids, 62(2), 107-110. http://dx.doi.org/10.1054/plef.1999.0128. PMid:10780875

Vallverdú-Queralt, A., Arranz, S., Medina-Remón, A., Casals-Ribes, I., \& Lamuela-Raventós, R. M. (2011a). Changes in phenolic content of tomato products during storage. Journal of Agricultural and Food Chemistry, 59(17), 9358-9365. http://dx.doi.org/10.1021/jf202140j. PMid:21819081

Vallverdú-Queralt, A., Regueiro, J., Martínez-Huélamo, M., Alvarenga, J. F. R., Leal, L. N., \& Lamuela-Raventós, R. M. (2014). A comprehensive study on the phenolic profile of widely used culinary herbs and spices: Rosemary, thyme, oregano, cinnamon, cumin and bay. Food Chemistry, 154, 299-307. PMid:24518346. http://dx.doi.org/10.1016/j. foodchem.2013.12.106

Vallverdú-Queralt, A., de Alvarenga, J. F. R., Estruch, R., \& LamuelaRaventos, R. M. (2013a). Bioactive compounds present in the Mediterranean sofrito. Food Chemistry, 141(4), 3365-3372. http:// dx.doi.org/10.1016/j.foodchem.2013.06.032. PMid:23993494

Vallverdú-Queralt, A., Oms-Oliu, G., Odriozola-Serrano, I., LamuelaRaventós, R. M., Martín-Belloso, O., \& Elez-Martínez, P. (2013b). Metabolite profiling of phenolic and carotenoid contents in tomatoes after moderate-intensity pulsed electric field treatments. Food Chemistry, 136(1), 199-205. http://dx.doi.org/10.1016/j. foodchem.2012.07.108. PMid:23017413

Vallverdú-Queralt, A., Oms-Oliu, G., Odriozola-Serrano, I., LamuelaRaventós, R. M., Martín-Belloso, O., \& Elez-Martínez, P. (2012). Effects of pulsed electric fields on the bioactive compound content and antioxidant capacity of tomato fruit. Journal of Agricultural and Food Chemistry, 60(12), 3126-3134. PMid:22372526. http://dx.doi. org/10.1021/jf205216m

Vichi, S., Zitterl-Eglseer, K., Jugl, M., \& Franz, C. (2001). Determination of the presence of antioxidants deriving from sage and oregano extracts added to animal fat by means of assessment of the radical scavenging capacity by photochemiluminescence analysis. Food/ Nahrung, 45(2), 101-104. PMID: 11379280

Wojdyło, A., Oszmiański, J., \& Czemerys, R. (2007). Antioxidant activity and phenolic compounds in 32 selected herbs. Food Chemistry, 105(3), 940-949. http://dx.doi.org/10.1016/j.foodchem.2007.04.038. 